\title{
O papel da imagem mental no raciocínio operatório: auxiliar ou estruturante?*
}

\section{Effects of mental imagery on operatoire reasoning: auxiliary or structuring effects?}

\author{
Magali Bovet** \\ Daphné Voelin***
}

\begin{abstract}
RESUMO
O objetivo deste estudo é examinar em crianças de 6 e 7 anos o efeito de uma aprendizagem figural sobre a resolução de problemas numéricos e geométricos compreendidos habitualmente na idade de 10 ou 11 anos. A hipótese geral é de que a imagem mental - ou o conhecimento figural - tem a função de estruturar o raciocínio operatório, enquanto Piaget e Inhelder sugeriram que ela só teria o papel de auxiliar. Os resultados mostram que um progresso considerável acontece durante e após a fase de aprendizagem quando as crianças têm representações corretas. Esse não é o caso quando suas imagens mentais estão erradas. Assim, a representação por imagem é um modo figural de base para o tratamento da informação que parece ser necessário ao desenvolvimento do raciocínio operatório. O papel estruturante da imagem mental é discutido.

Palavras-chave: imagem mental; aprendizagem figural; raciocínio operatório.
\end{abstract}

* Traduzido por Marta Teixeira do original em francês Le rôle de l'image mentale dans le raisonnement opératoire: auxiliaire ou structurant?, publicado na revista Enfance, n. 2, p. 175-195, 2003. Revisão de Tania Stoltz.

** Agradecemos aos especialistas por suas notas a respeito do manuscrito deste artigo.

Agradecemos a Olivier Renaud e Ralph Schmidt (FaPSE, Seção de Psicologia, Universidade de Genebra) por suas contribuições às analises estatísticas apresentadas neste artigo.

${ }^{* * *}$ Seção de psicologia, Universidade de Genebra Uni Mail, 40, Boulevard du Pont d'Arve, 1211, Genebra 4. 


\begin{abstract}
The goal of this study is to determine the effect of training in figural representations of numerical and geometrical transformations. Subjects were 6 and 7 years old, and the problem used is usually grasped at 10 or 11 years. The general hypothesis is that mental imagery, or figurative knowledge, structures "operatoire" reasoning and is not merely an auxiliary process, as Piaget and Inhelder suggested. Results show that children made important progress during and after the training phase if and when they formed correct visual images. By contrast, children whose imagery was poorly elaborated did not progress. As expected, visual imagery seems to play a necessary and structuring role for the development of "operatoire" reasoning.
\end{abstract}

Key-words: mental imagery; operatoire reasoning; figurative training.

Em que a imagem mental contribui para a gênese das coordenações operatórias subjacentes ao desenvolvimento mental?

O estudo da representação por imagem se desenvolveu, principalmente, no campo da concepção piagetiana e no campo do tratamento da informação. A perspectiva piagetiana é desenvolvimental, enquanto a outra corrente de trabalhos se preocupou de início com a imagem no adulto (DENIS, 1989; Lautrey; Chartier, 1987, 1991). Em seguida e recentemente, a dimensão desenvolvimental tornou-se mais ampla, como testemunham as obras de Bideau e Courbois (1998).

No campo do tratamento da informação, vê-se uma controvérsia entre os modelos analógico e proposicional. O caráter analógico da representação foi defendido por vários pesquisadores (PAVIO, 1977; KossLYn, 1980; SHEPARD; COOPER, 1982), que evidenciavam o aspecto particular do modo por imagem em seu caráter de isomorfismo entre os objetos e a representação destes. Ao contrário, para os partidários dos modelos proposicionais (PYLYSHYN, 1973, 1981; FoDOR, 1975), predomina um tipo de representação amodal em que a relação entre significante e significado é arbitrária. A representação se funda sobre as relações abstratas, independentemente do contexto.

Para a escola piagetiana genebresa, os dois aspectos das funções cognitivas, figurativos e operativos, se diferenciam essencialmente pelo fato de que os primeiros se remetem aos estados ou às configurações, enquanto os segundos - cujas raízes estão localizadas nos esquemas sensório-motores - concernem às transformações e suas coordenações.

Para essa escola, o funcionamento dos instrumentos figurativos é geneticamente subordinado ao das operações. A posição epistemológica 
antiempirista de Piaget o tinha conduzido a negligenciar o estudo do papel eventualmente construtivo dos instrumentos figurativos, para reter, sobretudo, o estudo do efeito do funcionamento operativo sobre a imagem mental, a memória e a percepção (Piaget, 1961; Piaget; Inhelder, 1996; Piaget; INHELDER, 1968).

Diferenças entre Piaget e os defensores do tratamento da informação, quanto a suas concepções teóricas e metodológicas, levam à pergunta: são os mesmos processos que são estudados?

A teoria de Piaget e os modelos proposicionais se distinguem da hipótese analógica porque eles postulam a existência de um só modo de estruturação dos conhecimentos gerando diversas formas de representação que lhe são subordinadas. O modelo de representação analógica defende, ao contrário, uma pluralidade de tipos de estruturação das representações.

Do ponto de vista metodológico, os pesquisadores piagetianos pedem à criança para que ela explicite sua representação verbalmente e graficamente pelo desenho. Na outra abordagem, o sujeito tem por tarefa simplesmente reconhecer um estímulo-padrão apresentado sob ângulos diversos - rotação imaginada (SHEPARD; COOPER, 1982) - entre uma série de estímulos nos quais alguns são a imagem desses no espelho.

As dificuldades observadas na criança nas pesquisas piagetianas estariam ligadas às insuficiências da imagens ou aos modos de realização requisitados?

O paradigma experimental da rotação imaginado de Shepard foi adaptado por Marmor $(1975,1977)$ para estudá-lo com crianças, acrescentando a ele provas operatórias. Alguns dos resultados desses trabalhos não confirmam os dados piagetianos, enquanto outras experiências trazem resultados compatíveis (DEAN, 1979; DeAn; Scherzer, 1982). Analisado por Lautrey e Chartier (1987), um estudo sustenta a hipótese de que os dois paradigmas experimentais, piagetiano e analógico, pedem dois modos de representação distintos (DEAN; SCHERZER; CHABAUD, 1986): um relativamente independente do desenvolvimento das operações, que permitiria antecipar o resultado de uma transformação sem capacidade de explicitar suas etapas, enquanto o outro modo, compatível com os modelos proposicionais e a teoria piagetiana, decomporia os momentos de transformação e os recomporia por meio de operações ou regras.

$\mathrm{Na}$ ótica cognitivista do tratamento da informação, o suporte imaginado e os processos de análise comportam propriedades intrínsecas e são inatos, o que implica uma concepção quantitativa do desenvolvimento que seria ligada ao acúmulo das experiências. A concepção da imagem de Piaget centra-se sobre o nível de conceituação e sobre a adequação da representação ao real. Para 
Piaget, o desenvolvimento do nível de significação da imagem é qualitativo e depende da evolução dos conhecimentos estruturados do sujeito.

A concepção analógica evoluiu e tornou-se mais complexa por causa da integração de novos dados neuro-anatômicos e fisiológicos. Além do mais, Kosslyn, em seguida (1994), vai reconsiderar mais geralmente o papel da motricidade na imagem, conferindo-lhe uma função nas imagens mentais de transformação.

O fato de atribuir um papel à dimensão motora na explicação da imagem já era central na teoria piagetiana a respeito da gênese da imagem mental (Piaget; Inhelder, 1966-1969). Conforme esses autores, a imagem mental não deve ser considerada como uma cópia do real regida unicamente pela percepção. Uma reconstrução ativa está em jogo, o que requer "uma intervenção necessária da motricidade" (PIAGET; INHELDER, 1963, p. 79).

Piaget distingue as imagens estáticas, que dizem respeito à representação de estados, e as imagens de transformação, que se referem às etapas de uma modificação quando da representação de um processo de mudança.

Uma outra distinção se refere aos aspectos reprodutivo ou antecipatório da imagem, conforme o que está por ser representado foi observado ou deve ser imaginado.

Os fatos recolhidos em numerosas experiências mostram principalmente que, do ponto de vista desenvolvimentista, a representação imaginada das configurações estáticas precede a das transformações. Esta última necessita do suporte das operações e sua elaboração a sucede. O desenvolvimento da imagem parece, logo, para Piaget, estar subordinado ao desenvolvimento das operações.

Lembremos o pensamento de Wallon (1942), para quem a imitação constituía, como para Piaget, um instrumento de transição entre as ações sensóriomotoras e as representativas. Mas Wallon atribuía aos processos imitativos um papel formador segundo o qual a ciência cria seu objeto, enquanto nossos pensamentos tendem a reproduzi-la. A concepção epistemológica de Piaget considera, ao contrário, que a ciência visa a transformar o objeto e que a figuração está subordinada a ela.

Nas experiências que seguem, procuramos explorar o papel que pode ter a imagem mental na construção de uma nova forma de raciocínio.

Numerosas pesquisas (por ex. Gillièron, 1980; Montangero, 1980; Chapman, 1988) mostraram que o funcionamento das estruturas operatórias é tributário dos conteúdos concretos particulares a cada problema, evidenciando, assim, sobre os processos de acomodação. Já que a imagem mental - que repousa sobre a imitação sensório-motora - está localizada ela mesma no pólo da acomodação da adaptação, ela deveria ter um papel na evolução do raciocínio. 
A problemática deste estudo pode se vincular, por outro lado, à idéia de modelos organizadores (MORENo et al., 1998), participando ao mesmo tempo da realidade e dos processos cognitivos. Nessa concepção, a representação imaginada interviria como organizador do conhecimento da mesma forma que as estruturas operatórias lógicas que constituiriam um sistema de organização particular ideal.

Piaget e Inhelder (1966) atribuíam à representação figural um papel auxiliar no desenvolvimento cognitivo. Nossa hipótese, ao contrário, é que se trata de um papel estruturante na evolução do raciocínio.

Se se afirma que a construção de um raciocínio lógico pode ser acelerada por exercícios que incitam explicitamente o sujeito a utilizar instrumentos figurativos, nossa posição será reforçada. Pareceu-nos, então, pertinente colocar nossa hipótese à prova num contexto de aprendizagem.

As pesquisas genebresas sobre a aprendizagem operatória (INHELDER; Sinclair; Bovet, 1974) tinham introduzido exercícios nos quais os aspectos figurativos e operativos não eram diferenciados como tais. Os resultados tinham sido analisados em termos operatórios globais, isto é, como coordenações de ações sensório-motoras ou operatórias.

Nossa problemática nos impõe uma distinção entre aspectos figurativos e operativos nos exercícios de aprendizagem, mesmo sendo, de fato, difícil tratar concretamente um aspecto separadamente do outro. Parece-nos, no entanto, apropriado falar disso em termos relativos.

\section{Experiência I}

\section{Método}

Escolhemos colocar aos sujeitos o problema da dupla diferença - anteriormente estudado em Genebra num outro contexto (SZEMINSKA, 1968) -, cuja resolução repousa sobre o sistema das estruturas operatórias concretas.

Sejam duas quantidades iguais, $\mathbf{A}$ e $\mathbf{B}$; uma parte $\mathbf{x}$ de uma é transferida para a outra. Estando escondida a quantidade A, o sujeito deve encontrar a resposta de como igualar novamente as duas quantidades, por uma quantidade y exterior a $\mathbf{A}$ e $\mathbf{B}$. A diferença a completar entre $\mathbf{A}$ e $\mathbf{B}$ é o dobro da quantidade transferida. A igualação necessita sempre de uma adjunção $\mathbf{y}=\mathbf{2 x}$ na quantidade diminuída. Essa lei funcional só é descoberta espontaneamente na idade de 10 a 11 anos. 


\section{População}

Somente os sujeitos que conservam o número são selecionados: 40 alunos que freqüentam as escolas primárias genebresas (primeira série do primário, idade média $6 ; 7$ - segunda série do primário, idade média 7;6). Vinte sujeitos constituem o grupo experimental que segue os exercícios na ordem descrita abaixo, e vinte sujeitos formam o grupo controle, que só faz os pré-testes e pós-testes.

\section{Situação experimental}

Apresentamos esse problema sob duas formas: dupla diferença numérica (designada neste estudo por $\mathbf{d d N}$ : coleções de amêndoas) e dupla diferença espacial (designada neste estudo por ddC: comprimentos de fitas).

No pré-teste, em uma primeira fase, a fim de conhecer o nível dos raciocínios espontâneos do sujeito, colocamos o problema numa situação na qual a criança não pode contar os elementos (aproximadamente vinte a trinta, dispostos aleatoriamente) nem medir exatamente os comprimentos das fitas. A igualdade inicial das quantidades em jogo, estabelecida por correspondência termo a termo, é admitida pela criança, e o valor da quantidade $\mathbf{x}$ transferida é evidenciado de forma muito clara.

Dois tipos de exercícios de aprendizagem - dos quais alguns de natureza figurativa e outros de natureza operativa - se desenrolam em seguida. Durante esses exercícios, duas coleções de um pequeno número de elementos ( 5 a 8 amêndoas) - ou dois comprimentos (fitas de $20 \mathrm{~cm}$ ) - são dispostos um sob o outro, em correspondência termo a termo ou em coincidência.

\section{Exercícios figurativos}

Após a constatação de sua igualdade inicial, uma das duas quantidades é escondida sob um túnel de papelão (designaremos sempre por $\mathbf{A}$ a quantidade escondida). Em seguida, A será aumentada (transferência de uma parte de B para A) ou diminuída (transferência de uma parte de $\mathbf{A}$ para B), a criança ficando bem atenta ao valor do que foi transferido. 


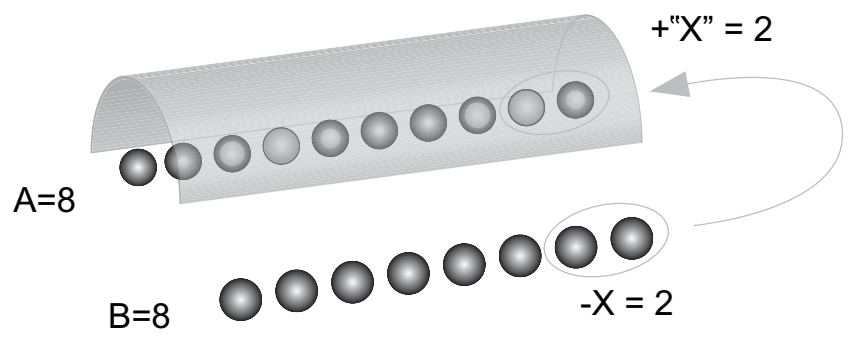

FIGURA 1 - TRANSFERÊNCIA DE 2 ELEMENTOS DE B PARA A

Antes da instrução de nova igualação, o sujeito é convidado a representar o novo estado da coleção (ou comprimento) A, escondida. "Onde você acha que acaba agora a linha que está escondida sob o túnel? Mostre-me."

Assim, ao mesmo tempo em que a criança pode constatar o efeito da transferência sobre uma das quantidades, a que fica visível, solicita-se à criança para imaginar o resultado da outra transformação (isto é, pede-se para que ela represente a diminuição ou aumento de $\mathbf{A}$, invisível). Esse apelo à imagem mental poderia ajudar a saber que existe uma relação entre as duas transformações em jogo.

\section{Exercícios operativos}

Procura-se evidenciar a dupla dimensão da transformação: adição e subtração. Como acima, uma das duas quantidades, A, é escondida. Em vez de desenrolar-se de uma só vez, as ações de subtração e adição são efetuadas em duas etapas sucessivas, entre as quais a quantidade $\mathbf{x}$ subtraída é deixada, bem visível, a meio caminho, e não acrescentada a $\mathbf{B}$ (ou a $\mathbf{A}$ ).

Pergunta-se, então, o que se precisaria acrescentar em A (ou em B) para restabelecer a igualdade. Toma-se nota da resposta da criança sem efetuar a adição que ela propôs. A diferença a completar neste momento equivale simplesmente à subtração.

Em uma segunda etapa, finaliza-se a transferência de $\mathbf{x}$ para $\mathbf{B}$ (ou para A): "E agora, quanto você acha que precisaria acrescentar para que nós dois tenhamos o mesmo número (ou o mesmo comprimento)?" 


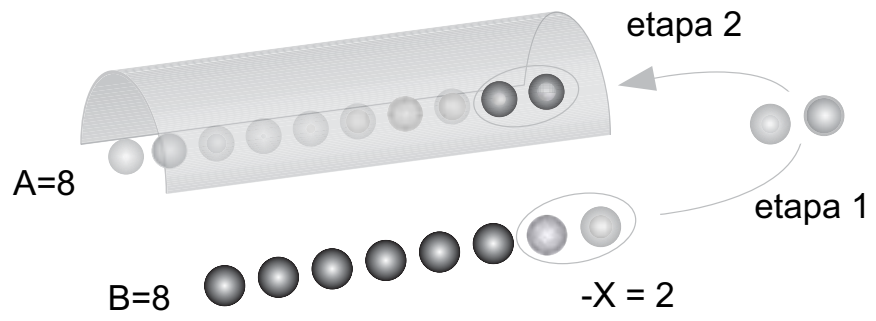

As fases da experiência

A experiência se desenrola em quatro sessões e o método de interrogação segue os princípios do método clínico-crítico piagetiano:

1. Pré-testes, quantidades dispostas aleatoriamente: ddN em seguida ddC (respectivamente problema da dupla diferença numérica depois de comprimento).

2. a) Exercícios figurativos, quantidades alinhadas e dispostas em correspondência: problemas ddN, depois ddC.

b) Controle intermediário: quantidades dispostas aleatoriamente, ddN.

3. a) Exercícios operativos, quantidades alinhadas e dispostas em correspondência: problemas ddC, depois ddN.

b) Controle intermediário: quantidades dispostas aleatoriamente, ddN.

4. Pós-testes: quantidades dispostas aleatoriamente, ddN, depois ddC.

Os intervalos entre as três primeiras sessões são de sete a dez dias. Os pós-testes acontecem depois de cinco a seis semanas.

\section{Resultados}

Qualquer que seja a fase experimental, observamos os seis tipos de condutas seguintes:

\section{Nivel I: nenhuma compreensão}

1. A diferença acrescida é sempre igual à subtração $(\mathrm{y}=\mathrm{x})$ ou então ela é aumentada aproximadamente após várias constatações de erro, mas sem compreensão das razões. 
Nivel II: centralização nos resultados

1. Solução correta por cálculo mental (ou por estimação, para o comprimento) dos resultados de cada transformação, considerados sucessivamente ("Você tinha 8 ; você tem 6 , e eu tinha 8 então agora eu tenho $10.10-6=4$ ").

2. Compreensão intuitiva da relação $y>x$, mas sem quantificação correta ("Você pegou três de mim, então eu devo pegar quatro" - recusando-se a pegar somente três, mas sem explicação).

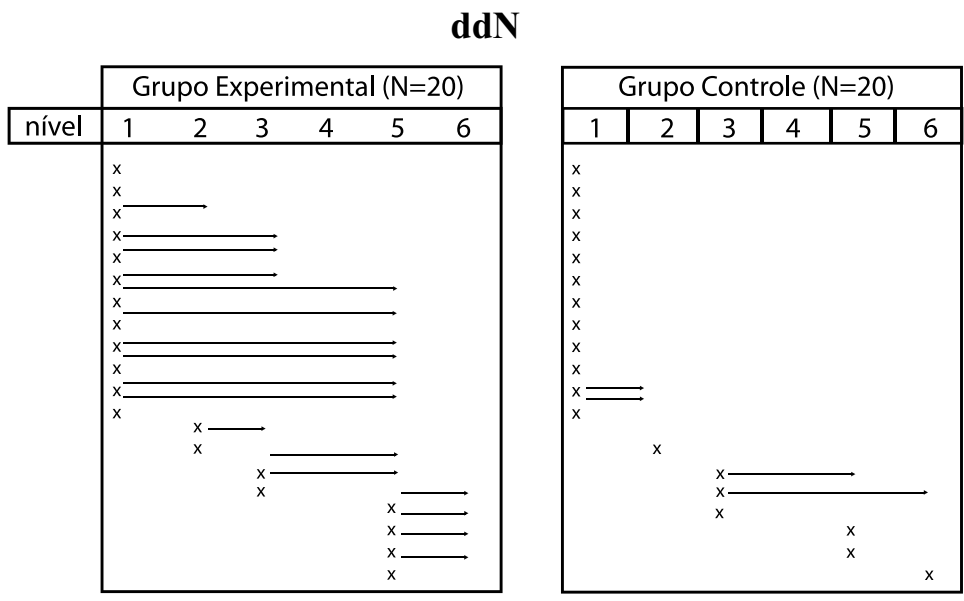

ddC
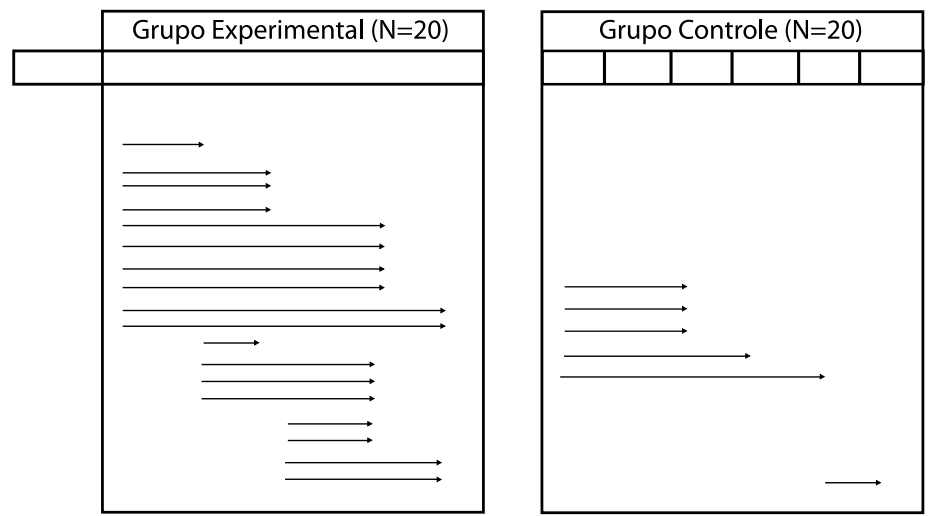

(x: nível no pré-teste. Flecha: evolução no pós-teste) 
QUADRO 1 - EVOLUÇÃO DOS NÍVEIS DE CONDUTA ENTRE PRÉ-TESTE E PÓS-TESTE ( $\mathrm{N}=40,6-8$ ANOS)

Nivel III: centralização nas transformações (ou diferenças)

1. Solução correta intuitiva: a criança imagina uma correspondência entre os $\mathbf{x}$ subtraídos e uma quantidade igual a $\mathbf{x}$ na outra coleção, depois os adiciona ("Você me deu 2, mas eu já os tinha, então você deve pegar 4").

2. Solução correta por raciocínio aditivo em relação às diferenças consideradas sucessivamente (- x e + x ) ("A você faltam 2, e eu, eu tenho 2 a mais. São 4").

3. Solução correta por raciocínio multiplicativo. A quantidade $\mathbf{x}$ é considerada como subtraída e acrescentada simultaneamente ("É preciso pegar o dobro porque o que você tirou daqui, você o deu para outro"). Generalização ("É preciso sempre pegar o dobro").

Para o conjunto dos sujeitos, os resultados são os seguintes:

Nos grupos experimentais, para ddN , 85\% (17 dos 20 sujeitos), e para ddC, $90 \%$ (18 dos 20 sujeitos) progridem entre o pré-teste e o pós-teste. Nos grupos-controle, somente 4 e 6 sujeitos, respectivamente, progridem (em torno de $25 \%$ ) e a amplitude de seu progresso é muito mais fraca que a dos sujeitos do grupo experimental.

Constatamos, então, no momento dos pós-testes, que os exercícios (figurativos e operativos, globalmente) revelam ser muito eficazes.

Examinemos agora em particular o papel dos exercícios figurativos nesse progresso. Procedemos a uma estimação ao longo da aprendizagem em relação à compreensão do problema ddC (1), anotando as condutas obtidas por cada sujeito neste problema após o último dos quatro exercícios figurativos e antes de qualquer exercício operativo. Já aparece um progresso - mais ou menos importante - em 15 dos 20 sujeitos.

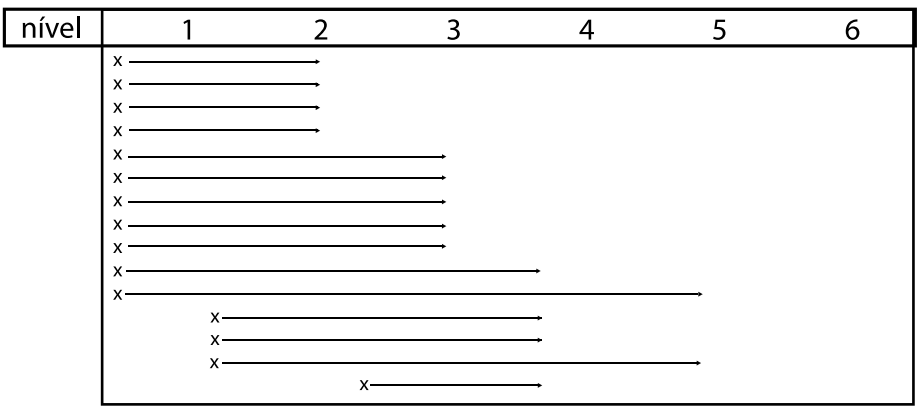


BOVET, M.; VOELIN, D. O papel da imagem mental no raciocínio operatório: auxiliar ou estruturante?

(x: nível no pré-teste. flecha: evolução após exercícios figurativos)

QUADRO 2 - EVOLUÇÃO DOS NÍVEIS DE CONDUTA PARA DDC, APÓS SOMENTE EXERCÍCIOS FIGURATIVOS (OBSERVADA EM 15 DOS 20 SUJEITOS, DE 6-8 ANOS)

\section{Discussão}

É impressionante que com a ajuda de exercícios crianças tão pequenas tenham conseguido construir raciocínios que parecem equivalentes àqueles encontrados somente a partir de 10 anos quando do desenvolvimento espontâneo. Os raciocínios complexos observados dizem respeito às relações entre transformações, isto é, às diferenças propriamente ditas.

Mas, sobretudo, é importante enfatizar que, após os argumentos avançados das crianças, as diferenças sobre as quais elas raciocinam são representadas figurativamente pelas imagens mentais.

Sugerimos falar de operações figurais, ou de raciocínio em um modo analógico para caracterizar as soluções corretas suscitadas pela aprendizagem.

Os resultados deste estudo exploratório nos conduzem às seguintes questões:

As "operações figurais" correspondem a um nível de raciocínio que precede aquele das estruturas operatórias e, se sim, o precedem necessariamente?

$\mathrm{Ou}$ as "operações figurais" caracterizam um modo de funcionamento sempre subjacente ao raciocínio lógico, mas que o sujeito pode escolher adotar por prioridade, em função da natureza ou da dificuldade do problema?

\section{Experiência II: aprendizagem figurativa}

O alcance de nosso primeiro estudo está evidentemente limitado pela organização experimental que comportava sucessivamente exercícios figurativos e operativos. Trata-se agora, em uma segunda experiência, de centrar-se somente na aprendizagem figural, a fim de explorar de maneira mais precisa a natureza das "operações figurais" e de analisar sua função estrutural na construção de um raciocínio operatório.

\section{Método}

O problema proposto às crianças permanece aquele da dupla diferença. Primeiramente, alargamos o leque dos exercícios figurativos. Em segundo 
lugar, introduzimos no pós-teste uma versão inversa do problema da dupla diferença (ver descrição acima), isso a fim de explorar uma eventual generalização da aprendizagem e de verificar a mobilidade do raciocínio adquirido.

\section{População}

Vinte e quatro sujeitos, meninos e meninas, de $6 ; 6$ a 7;6, que freqüentam a primeira série do primário de uma escola genebresa. Doze sujeitos constituem o grupo experimental e doze constituem o grupo-controle, que não participa das sessões de aprendizagem.

\section{Situações experimentais}

Os princípios dos três tipos de exercícios são os mesmos para ddN e ddC. Descrevemos abaixo somente os exercícios para os problemas numéricos, ddN.

\section{A. Imitação}

a) Sob duas fileiras de 8 a 10 amêndoas dispostas em correspondência termo a termo, é colocada uma folha sobre a qual são desenhadas duas longas fileiras de pequenos círculos que a criança usa para imitar todas as ações de transferência que se desenrolam e cujos resultados ela não vê (as coleções A e B são escondidas sob túneis). A criança indica, em diversos momentos, os lugares das amêndoas presentes (marcando-as com uma cruz) e os lugares vazios (que ela cobre com cartões).

Para ddC, as quantidades consistem em duas fitas de papel de $30 \mathrm{~cm}$, de uma das quais cortava-se um fragmento para o acrescentar à outra. A criança deve imitar o alongamento de uma e o encurtamento da outra resultante da transferência, em um dispositivo de escorregadiças.

b) Sem a folha desenhada, coloca-se para a criança o problema da dupla diferença: "Quantas amêndoas dar para A (ou B) para que haja o mesmo tanto em B (ou A)?"

A imitação das ações do experimentador - cujo resultado está escondido -, assim como a percepção do resultado das ações da criança (adição de cruz e de cartões), apela para as funções figurativas.

\section{B. Imagem mental}


a) Uma das duas quantidades (A) estando escondida sob um túnel, efetua-se a transferência de uma parte $\mathbf{x}$ de $\mathbf{A}$ para $\mathbf{B}$, ou de uma parte $\mathbf{x}$ de $\mathbf{B}$ para $\mathbf{A}$.

Convida-se o sujeito para que ele antecipe o novo estado - aumentado ou diminuído - da quantidade A escondida: "Até onde se estendem as amêndoas sob o túnel agora?"

Para ddC, o material consiste sempre em duas fitas de $30 \mathrm{~cm}$, uma das quais é escondida sob um túnel.

b) Coloca-se o problema da dupla diferença.

Este exercício apela diretamente para a imagem mental do resultado da transformação.

C. Figuração da simetria dos resultados das ações de subtração e adição.

a) As quantidades consistem em duas colunas de 10 cubos empilhados verticalmente sobre a mesa. Após a criança ter constatado a igualação inicial das duas pilhas, elas são escondidas por uma tela cuja extremidade superior chega à altura inicial das pilhas. Efetua-se uma transferência de uma pilha para outra. Após esse deslocamento, somente a quantidade transferida fica visível para a criança, já que ultrapassa a extremidade da tela.

O sujeito é convidado a imaginar onde se situa o topo escondido da quantidade diminuída e indicar sua altura na tela.

Para ddC, as quantidades consistem em dois canudinhos de mesmo comprimento dispostos verticalmente (amparados por duas hastes metálicas) e cuja extremidade corresponde à altura da tela.

b) O problema da dupla diferença é colocado da mesma maneira que para os itens anteriores.

Este exercício incita uma representação figural espacial da simetria das duas transformações (subtração e adição), já que a extremidade da tela indica exatamente a altura inicial das duas quantidades.

\section{Problema inverso (generalização)}

Sejam duas quantidades iguais A e B. Uma parte $\mathbf{x}$ de A é subtraída e "jogada fora".

O sujeito deve encontrar o meio de igualar novamente A e B pela transferência de uma quantidade $\mathbf{y}$ de $\mathbf{B}$ para $\mathbf{A}$. A diferença a completar entre $\mathbf{A}$ e B é a metade da quantidade retirada. 
A igualação necessita, então, sempre da transferência de $\mathbf{y}=\mathbf{x} / \mathbf{2}$ para a quantidade diminuída.

\section{Fases da experiência}

A metade dos sujeitos do grupo experimental $(\mathrm{N}=6)$ é confrontada com o problema numérico e a outra metade $(\mathrm{N}=6)$ ao do comprimento. A experiência se desenrola em quatro sessões:

1. Pré-teste, quantidades dispostas aleatoriamente ddN (ou ddC).

2. Exercícios de aprendizagem, na ordem A, B, C (ddN ou ddC).

3. Exercícios de aprendizagem, na ordem C, B, A (ddN ou ddC).

Para as sessões 2 e 3 , cada tipo de exercício comporta dois itens nos quais se varia o valor do $\mathbf{x}$ transferido. Para cada item, solicita-se uma resposta em relação à representação figural e um raciocínio concernente ao problema da dupla diferença. Obtêm-se assim doze respostas por criança em cada sessão.

4. Pós-teste: retomada do pré-teste, em seguida apresentação do problema inverso como generalização.

O intervalo entre as três primeiras sessões era de 7 a 10 dias. A quarta sessão aconteceu 4 a 5 semanas mais tarde.

O grupo-controle foi testado duas vezes, com um intervalo correspondente ao que separa os pré-testes e pós-testes do grupo experimental.

\section{Resultados}

Sobre o raciocínio, os seis níveis de conduta observados permanecem aqueles estabelecidos quando do primeiro estudo. Os níveis de representação são os seguintes:

a. Erros de representação sem melhora (ex.: o sujeito indica por cruzes as amêndoas acrescentadas, mas não elimina as deslocadas da outra coleção).

b. Erros de representação, corrigidos em um segundo tempo (ex.: idem acima, mas após questionamento do experimentador, a criança efetua a segunda transformação).

c. Aproximação, sem contar para ddN nem usar a medida para ddC (ex.: a criança indica que a altura da torre escondida diminuiu, mas de maneira inexata, "ela está por aqui" mostrando uma altura qualquer, corretamente orientada mas imprecisa, apesar da insistência do experimentador).

d. Aproximação, mas especificada em um segundo tempo (após questionamento do experimentador, a criança conta os elementos ou usa uma medida corretamente). 
e. Resposta correta logo de início.

A evolução das condutas após aprendizagem é apresentada nos quadros abaixo.

Enquanto as pesquisas genebresas sobre a aprendizagem operatória (Piaget e GréCo, 1959; InHelder et al., 1974) atribuem o progresso obtido ao funcionamento apenas dos aspectos operativos da cognição, observamos que nossos exercícios que apelam para os aspectos figurativos produzem igualmente um efeito positivo na compreensão dos problemas em questão. ${ }^{1}$

A fim de analisar os efeitos dos exercícios figurais, examinemos as ligações entre a qualidade da representação figural quando dos exercícios A, B, C e o nível de raciocínios para os problemas da dupla diferença correspondentes. Com o objetivo de testar nossos resultados por meio de um índice estatístico (Collett, 1991), reagrupamos os níveis de representação (de $\mathrm{Aa} \mathrm{C}$ e de $\mathrm{D} \mathrm{aE}$ ) por um lado e os níveis de raciocínio por outro (de 1 a 3 e de 4 a 6 ).
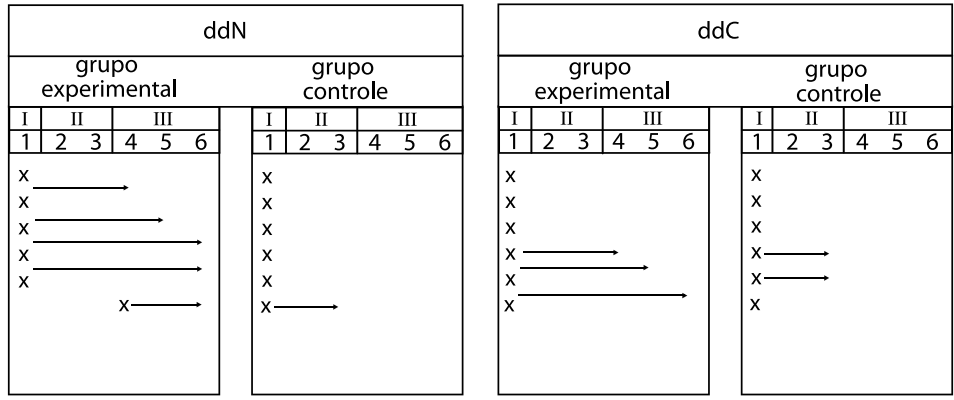

Abscissa: nível das condutas / Ordenada: sujeitos / " $\mathrm{x}$ ": conduta pré-teste/ $\longrightarrow$ : conduta pós-teste.

QUADRO 3 - EVOLUÇÃO DOS NÍVEIS DAS CONDUTAS ENTRE PRÉ-TESTE E PÓS-TESTE (N = 24, 6-7 ANOS)

${ }^{1} \mathrm{O}$ progresso mais importante anotado para $\mathbf{d d N}$ que para $\mathbf{d d C}$ está provavelmente ligado à defasagem do desenvolvimento em favor do campo lógico-matemático observado nos diversos estudos transversais piagetianos. 


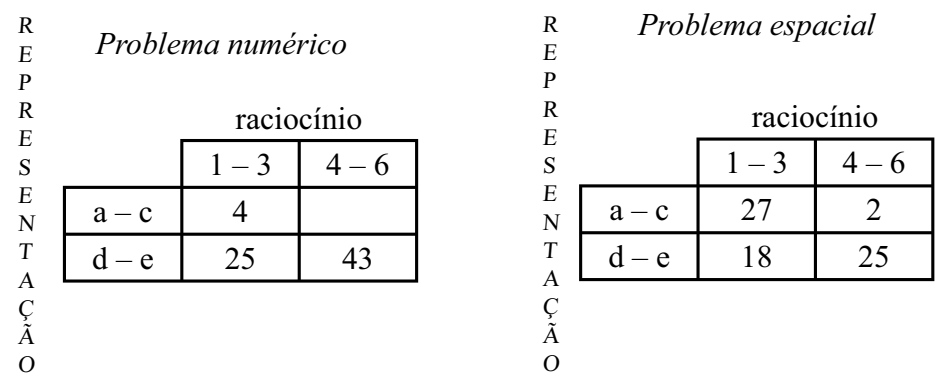

QUADRO 4 - COMPARAÇÃO ENTRE NÍVEIS DE REPRESENTAÇÃO E DE RACIOCÍNIO QUANDO DOS 12 EXERCÍCIOS DURANTE A APRENDIZAGEM ( $+12,6-7$ ANOS)

Para a dupla diferença numérica, obtém-se um valor estimado de 1 . O intervalo de confiança para o índice Del é de -0,51 a 1 . Esse resultado não permite diminuir estatisticamente a independência entre os níveis de raciocínio e os de representação, mas isso provavelmente se deve ao fato de que a maioria das respostas de representação (68/72) era de nível elevado, o que não é o caso para os problemas espaciais $(43 / 72)$.

Para a dupla diferença de comprimento, obtém-se um valor estimado de 0,82 . $\mathrm{O}$ intervalo de confiança para o índice Del é de 0,35 a 0,98 . Esse resultado vai muito significativamente contra a hipótese de independência entre o nível do raciocínio e o da representação.

\section{Discussão}

Encontramos os seguintes fatos:

1. Quando os exercícios figurais suscitam representações corretas, os sujeitos conseguem gradualmente apreender os problemas de dupla diferença a um nível superior, enquanto o raciocínio deles era pré-operatório no préteste.

2. A imagem correta ("e" ou "d") não está sempre de acordo com um raciocínio de nível elevado (nível 4, 5 ou 6), mas enfatizamos que um raciocínio de nível elevado não se observa jamais em sujeitos cuja imagem é inadequada (nível a ou b).

3. Para o problema ddN, a representação figural era, em geral, de início correta. A maioria dos sujeitos marcou um nítido progresso de raciocínio desde a primeira aprendizagem.

4. Por outro lado, para o problema ddC, a representação era, em geral, falsa ou aproximativa, e o raciocínio dos sujeitos não progrediu.

Esses resultados seguem no sentido de nossa hipótese sobre o papel construtivo da representação figural. Lembremos que os desempenhos observados após a 
aprendizagem nessas crianças de 6 a 7 anos só se encontram nas crianças de aproximadamente 10 anos nos estudos transversais.

\section{Experiência III: comparação dos problemas de dupla diferença diretos e inversos: estudo desenvolvimental}

A fim de evidenciar uma eventual generalização da aprendizagem, comparamos os níveis de conduta no momento do pós-teste com os níveis obtidos nos problemas inversos.

Ficamos surpresos ao constatar que a maioria das crianças tinha resolvido o problema inverso a um nível melhor que aquele de seu raciocínio no pósteste do problema da dupla diferença. Este último não foi útil para o estudo de uma eventual generalização. Por outro lado, esse resultado nos sugeriu que era possível ligar essa defasagem a uma questão de representação figural.

Intentamos, sem aprendizagem, um estudo desenvolvimental dos raciocínios nas versões direta e inversa, a fim de comparar essas duas versões do mesmo problema. Estas, mesmo sendo formalmente equivalentes, parecem não sê-lo quanto à sua dificuldade. Perguntamo-nos se a diferença observada era ligada ao nível operatório dos sujeitos e/ou à intervenção dos instrumentos figurativos que seriam solicitados diferentemente no momento da resolução do problema segundo a versão em questão.

\section{Método}

\section{População}

Quarenta e seis sujeitos de 6 a 11 anos, meninos e meninas, alunos de uma escola primária genebresa da $1^{\mathrm{a}}$ a $6^{\mathrm{a}}$ séries $(\mathrm{N}=12$ de 6 a 7 anos, $\mathrm{N}=11$ de 7 a 8 anos, $\mathrm{N}=11$ de 8 a 9 anos e $\mathrm{N}=12$ de 9 a 11 anos).

\section{Procedimento da experiência}

Cada sujeito foi interrogado em uma só sessão, para as situações seguintes: ddN e $\mathbf{d d C}$ na versão direta, $\mathbf{d d N}$ e $\mathbf{~ d d C}$ na versão inversa. Cada situação era apresentada em disposição aleatória e comportava dois itens com valores diferentes de $\mathbf{x}$. A criança não tinha, de forma alguma, a possibilidade de verificar a solução que propunha. 
A ordem de apresentação das quatro situações era neutralizada por contrabalanceamento.

\section{Resultados}

Para o problema direto, as condutas são as já observadas.

Para o problema inverso, as condutas foram classificadas de $\mathbf{1}$ a $\mathbf{6}$ da seguinte maneira:

\section{Nível I: Nenhuma compreensão}

1. A quantidade transferida é igual à quantidade descartada $(\mathrm{x}=\mathrm{y})$.

\section{Nivel II: centralização nos resultados}

2. O sujeito declara que o problema não tem solução após várias tentativas de cálculo ("eu tenho dois a menos, mas se você me der 2 , é você que terá menos... você tem 7 , eu tenho 5 , se você me desse os 2 que eu joguei, eu é que teria 7 e você $5 .$. é impossível").

3. O sujeito compreende intuitivamente a relação $\mathbf{x}<\mathbf{y}$, mas sem a quantificar corretamente e sem poder dar uma explicação válida ("você jogou 4, eu devo te dar 3", recusando dar 4, "você terá demais").

Nivel III: centralização nas transformações ou diferenças

4. A solução está correta, mas a justificativa é intuitiva e parcial. Uma bipartição do valor $\mathbf{x}$ é proposta em um segundo momento ("Você jogou 4 dos teus, então eu dou-te 4 dos meus... ah não: você é que terá demais, então eu te dou 2 e fico com 2").

5. A solução está correta por subtração ("Você jogou 4, então eu tenho 4 a mais que você; te dou 2 , porque $2+2=4$ ").

6. A solução está correta por divisão ("É preciso que eu te dê a metade").

Comparemos as condutas referentes aos problemas direto e inverso:

Dois terços dos sujeitos (30/46 para ddN e 31/46 para $\mathbf{d d C}$ ) tratam dos problemas inversos em um nível superior ao dos problemas diretos. Menos de um quarto dos sujeitos tem um raciocínio que se situa no mesmo nível para os dois problemas, tanto para o campo numérico quanto para o espacial (10/46 e 9/46 respectivamente). Assim, para o conjunto de nossa amostra (6 a 11 anos), os problemas diretos e inversos, formalmente equivalentes, revelam-se 
efetivamente resolvidos em níveis desiguais.

Com o objetivo de testar o significado das diferenças entre os desempenhos nos problemas diretos e nos problemas inversos, escores de diferença foram calculados subtraindo, para cada sujeito e para as duas tarefas (numérica e espacial), o nível de conduta no problema inverso daquele do problema direto ( $\mathrm{D}$ = nível de conduta no problema direto; $\mathrm{I}$ = nível de conduta no problema inverso; D - I = escore de diferença). Com base nesses escores de diferença, um teste $t$ foi realizado para a tarefa numérica e para a tarefa espacial, respectivamente. Nos dois casos, a hipótese nula pôde ser rejeitada com uma probabilidade de erro $\mathbf{p}<\mathbf{0 , 0 1}$. A superioridade dos níveis de conduta nos problemas inversos revela-se, logo, estatisticamente altamente significativa.

Examinemos os níveis das condutas para cada uma das versões ao longo do desenvolvimento.

Para o conjunto da população e para os dois problemas, constatamos os seguintes fatos:

As condutas de nível $\mathbf{1}$ (solução $\mathbf{x}=\mathbf{y}$ ) são muito freqüentes nos problemas diretos e estão presentes até 11;6 anos. Nos problemas inversos, elas estão quase ausentes.

As condutas que aparecem de maneira característica nos problemas inversos são aquelas de nível 2 ("não há solução possível") e $\mathbf{4}$ (solução correta com justificativa intuitiva).

As condutas de nível 2 nunca aparecem sob esta forma para os problemas diretos, em que o cálculo permite atingir uma solução correta.

As condutas de nível 4 (soluções corretas, intuitivas) são ao mesmo tempo precoces e mais freqüentes para os problemas inversos que para os problemas diretos.

\section{Discussão}

Nas duas versões do problema, direto e inverso, trata-se de procurar um meio para restabelecer uma igualdade de partida. O primeiro dado que o sujeito deve considerar é o fato de que uma parte de uma das duas quantidades em questão foi subtraída e transferida. O segundo dado é a conseqüência dessa transferência, que é singular para o problema inverso (é uma diminuição seja de A seja de B) e composta para o problema direto (diminuição de $\mathbf{A}$ e aumento correlativo de $\mathbf{B})$.

Ora, para a maioria dos sujeitos - independentemente da versão do problema -, a reação espontânea inicial é a de centrar-se unicamente seja na diminuição seja no aumento de uma das duas quantidades e visualizar uma conseqüência singular. O que diferencia as duas versões do problema é a 
ordem de sucessão das diferentes operações em questão.

Se abordarmos o problema figuralmente, é mais fácil representar corretamente a diferença a quantificar no problema inverso: ela é determinada, desde a partida, pela quantidade subtraída e ela é representável facilmente, já que concretizada perceptivamente pela quantidade que ultrapassa na coleção (ou no comprimento) aumentada. Para o problema direto, duas transformações devem ser compostas. Para este último, nossos resultados nos mostraram que os exercícios de aprendizagem figural facilitaram a construção (cada vez mais próxima) de uma representação inicial correta da diferença e que no momento dos exercícios figurais uma representação da imagem correta tinha sido geralmente seguida de um progresso do raciocínio.

Examinemos agora nossos resultados segundo esta análise:

A respeito do problema inverso, as crianças que adotam a conduta de nível 2 (aqueles que, rejeitando a solução inferior de nível 1, pensam que o problema não tem solução), o fazem apoiando-se na representação das configurações. De fato, suas justificativas do tipo: "Olha: você jogou essas três, faltam três para você. Se eu te der três dos meus, faltarão três para mim. Então não dá certo. Não dá pra fazer assim." demonstram uma abordagem essencialmente figurativa.

Quanto aos raciocínios de nível 4, que chamamos de intuitivos, eles consistem, após ter visualizado como primeira solução a transferência de $\mathbf{x}$, de $\mathbf{B}$ para $\mathbf{A}$ (nível 1), em antecipar o resultado (B terá $\mathbf{x}$ de menos) e em rejeitá-lo. Mas, contrariamente aos sujeitos de nível $\mathbf{2}$, os raciocínios de nível $\mathbf{4}$ procedem cada vez mais próximos à bipartição dessa diferença $\mathbf{x}$ entre as duas quantidades. "Você jogou quatro dos teus. Se eu te der quatro dos meus, eu é que terei menos. Não dá certo...” Depois (a criança hesita e reflete um momento, separando e deslocando esses quatro elementos de sua quantidade) - "Ou então, eu poderia te dar dois, e guardo dois para mim".

É freqüente observar, ao longo do desenrolar do raciocínio de nível 4, tal passagem hesitante por uma conduta 2 . Esse fato reforça nossa interpretação de que a conduta correta de nível 4, encontrada muito mais freqüentemente no momento das versões inversas, tem base em um primeiro tratamento de natureza figurativa.

Para o problema direto, lembremos que, no momento dos exercícios de aprendizagem, o apelo à representação figural tinha ajudado na resolução do problema. A compreensão da dupla conseqüência da transferência de $\mathbf{A}$ para $\mathbf{B}$ - dado indispensável para resolver esse problema - tinha sido facilitada pelo material imaginado, $\mathrm{e}$ resultou daí um progresso operatório.

Assim, o fato de que a resolução do problema direto da dupla diferença seja mais tardia que a do problema inverso reforça nossa hipótese de início. O tratamento figurativo parece necessário (mesmo se não é suficiente) ao tratamento operativo ou lógico: tanto os exercícios figurativos de aprendizagem quanto um desenvolvimento da tarefa, que torna desde o início mais fácil a representação de seus dados (problema 
inverso), favorecem a construção operatória.

\section{Conclusões gerais}

Resumindo os dados principais que sobressaem de nosso estudo:

- Exercícios de aprendizagem que apelam para funções figurativas desencadeiam um raciocínio de um nível operatório superior àquele do raciocínio inicial.

- Os sujeitos progridem quando suas imagens mentais antecipatórias dos resultados da transferência são exatas.

- Nenhum raciocínio é correto quando as imagens antecipatórias são aproximativas ou falsas.

- Um tratamento operatório superior é mais precoce quando os dados do problema são facilmente representáveis figuralmente.

Assim, parece que as "operações figurais" não constituem elas mesmas um nível operatório geral. Elas caracterizam mais provavelmente um modo de funcionamento suscetível de ser ativado tal qual ou então em conjunção com as operações lógicas, conforme a natureza do problema.

No que diz respeito ao papel da imagem mental, vimos que a representação figural correta antecipada somente dos resultados das transformações sempre precedeu o tratamento operatório correto e o conjunto das relações complexas em questão. Por outro lado, quando as imagens estavam corretas, os exercícios figurais quase sempre foram seguidos por um progresso operatório.

Retomemos os resultados de um dos estudos de Piaget e Inhelder sobre a imagem mental (1966), aquela da "rotação das pérolas". Tratava-se de imaginar a modificação da ordem de três pérolas coloridas enfileiradas sobre uma haste quando esta sofria uma rotação de $180^{\circ}$ ou $360^{\circ}$, depois de desenhar ainda os trajetos dessas três pérolas durante as rotações. Um dos resultados principais era que a compreensão da inversão da ordem precede em alguns anos a representação figural dos trajetos das pérolas. Esse resultado indica que a compreensão lógica da mudança de ordem não deriva de uma representação por meio de imagem exata da transformação. Ela resulta, para os autores, de uma coordenação operatória de ações, isto é, de um tratamento operativo. Eles concluíram que o tratamento figurativo dos dados não tem função na estruturação operatória. Mas, de fato, a antecipação correta da inversão da 
ordem poderia bem ser também o produto de um primeiro tratamento que seria figurativo e não ainda operativo e poderia consistir em uma simples imagem antecipatória dos resultados das transformações. Essa imagem global e intuitiva precederia e seria uma condição necessária ao tratamento operativo posterior dos aspectos mais complexos da rotação. Esse tratamento operativo, por sua vez, permitiria a representação figural correta da própria transformação (direções, distâncias).

Nos nossos problemas de dupla diferença, a representação figural antecipada dos resultados das transferências de quantidades introduzidas pelo experimentador corresponde à antecipação das mudanças da ordem na situação da rotação das pérolas. A imagem mental dos estados modificados das coleções ou dos comprimentos parece ter sido um apoio necessário na relação operativa das transformações, já que nenhuma solução correta do problema foi observada quando essas imagens eram falsas. Além do mais, nossos resultados indicam que a representação figural tem um papel construtivo na microgênese do raciocínio, já que esse último evoluiu muito quando os exercícios figurais eram corretos no problema numérico, enquanto o raciocínio progrediu menos na situação espacial em que a representação por meio de imagem era mais difícil.

Citemos ainda Lautrey (1990, p. 87), que se refere ao paradigma experimental da rotação imaginada de Shepard (1982):

A pluralidade dos modos de representação e de tratamento levam também a repensar os mecanismos mesmos do desenvolvimento cognitivo [...] No caso da representação do movimento da rotação [...] pode-se perguntar se as antecipações precoces do resultado que repousam no processo analógico, implícito, de rotação mental, não contribuem [...] na direção da construção das operações espaciais pelas quais os sujeitos poderão em seguida conseguir uma representação controlada das etapas do desenvolvimento desse movimento.

Ele fala, então, de um "círculo auto-organizador". Nosso trabalho se propõe a reconsiderar o papel das funções figurativas no desenvolvimento operatório e a aprofundar o estudo de seu alcance quando do estabelecimento de um raciocínio lógico. 


\section{REFERÊNCIAS}

BIDEAUD, J.; COURBOIS, Y. Image mentale et développement. De la théorie piagétienne aux neurosciences cognitives. Paris: PUF, 1998.

CHAPMAN, M. Functions, operations and decalage in the development of transitivity. Developmental Psychology, v. 24, n. 4, p. 542-551, 1988.

COLLETT, D. Modelling binary data. Chapman \& Hall, 1991.

DEAN, A. L. Patterns of change in relation between children's anticipatory imagery and operatory thought. Development Psychology, n. 15, p. 153-163, 1979.

DEAN, A. L.; SCHERZER, E. A comparison of reaction time and drawing measures of mental rotation. Journal of Experimental Child Psychology, n. 34, p. 20-37, 1982.

DEAN, A. L.; SCHERZER, E.; CHABAUD, S. Sequential ordering in children's representations of rotation movements. Journal of Experimental Child Psychology, n. 42, p. 99-114, 1986.

DENIS, M. Image et cognition. Paris: PUF, 1989.

FODOR, J. A. The language of thought. New York: Thomas Y. Crowell, 1975.

GILLIERON, C. Réflexions sur le problème des décalages: à propos de l'article de J. Montangero. Archives de Psychologie, n. 48, p. 283-302, 1980.

INHELDER, B.; SINCLAIR, H.; BOVET, M. Apprentissage et structures de la connaissance. Paris: PUF, 1974.

KOSSLYN, S. M. Image and mind. Cambridge (MA): Harvard University Press, 1980.

. Image and brain: the resolution of the imagery debate. Cambridge (MA): Harvard University Press, 1994.

LAUTREY, J. Unicité ou pluracité dans le développement cognitif: les relations entre image mentale, action et perception. In: NETCHINE-GRYNBERG, G. (Org.). Développement et fonctionnement cognitifs chez l'enfant. Paris: PUF, 1990. p. 71-92.

LAUTREY, J.; CHARTIER, D. Images mentales de transformation et opérations cognitives: une revue critique des études développementales. L'Année Psychologique, n. 87, p. 581-602, 1987.

. A developmental approach to mental imagery. In: CORNOLDI, C.; 
BOVET, M.; VOELIN, D. O papel da imagem mental no raciocínio operatório: auxiliar ou estruturante?

MCDANIEL, M. A. (Orgs.). Imagery and cognition. New York: Springer Verlag, 1991. p. 247-282.

MARMOR, G. S. Development of kinetic images: when does the child first represent movement in mental images? Cognitive Psychology, n. 7, p. 548-559, 1975.

. Mental rotation and number conservation: are they related? Developmental Psychology, n. 13, p. 320-325, 1977.

MONTANGERO, J. The various aspects of horizontal decalage. Archives de Psychologie, n. 48, p. 259-282, 1980.

MORENO, M. et al. Conocimiento y cambio. Barcelona: Paidós, 1998.

PAIVIO, A. Images, propositions and knowledge. In: NICHOLAS, J. M. (Org.). Images, perception and knowledge. Dordrecht-Boston: Reidel, 1977.

PIAGET, J.; GRÉCO, P. Aprentissage et connaissance. Paris: PUF, 1959.

PIAGET, J. Les mécanismes perceptifs: modèles probabilistes, analyse génétique, relations avec l'intelligence. Paris: PUF, 1961.

PIAGET, J.; INHELDER, B. Les images mentales. In: FRAISSE, P.; PIAGET, J. (Dir.). Traité de psychologie expérimentale. VII. L'intelligence. Paris: PUF, 1963.

. L'image mentale chez l'enfant. Paris: PUF, 1966.

. Mémoire et intelligence. Paris: PUF, 1968.

PYLYSHYN, Z. W. What the mind's eye tells the mind brain: a critique of mental imagery. Psychological Bulletin, n. 80, p. 1-24, 1973.

. The imagery debate: analogue media versus tacit knowledge. Psychological Review, n. 88, p. 16-45, 1981.

SHEPARD, R. N.; COOPER, L. A. Mental images and their transformations. Cambridge (MA): The MIT Press, 1982.

SZEMINSKA, A.; PIAGET, J. La composition des différences: le partage inégal. In: PIAGET, J. et al. (Orgs.). Épistémologie et psychologie de la fonction. Études d'épistémologie génétique. XXIII. Paris: PUF, 1968. p. 93-101.

WALLON, H. De l'acte à la pensée. Paris: Flammarion, 1942. 